\title{
Antiretroviral Therapeutic Profile in Patients Living with HIV with Chronic Kidney Disease
}

\author{
Yawovi Mawufemo Tsevi ${ }^{*}$, Lidaw Déassoua Bawe ${ }^{2}$, Komi Dzidzonu Nemi ${ }^{3}$, \\ Abdou Razak Moukaila², Akessiwe Akouda Patassi², Majesté Ihou Wateba ${ }^{2}$
}

\footnotetext{
${ }^{1}$ Department of Nephrology and Hemodialysis, University Hospital Sylvanus Olympio of Lomé, University of Lome-Togo ${ }^{2}$ Departement of Infectious and Tropical Diseases, University Hospital Sylvanus Olympio of Lomé, University of Lome-Togo ${ }^{3}$ Department of Internal Medicine, University Hospital Sylvanus Olympio Lomé, University of Lome-Togo Email: *tseviclaude@gmail.com
}

How to cite this paper: Tsevi, Y.M., Bawe, L.D., Nemi, K.D., Moukaila, A.R., Patassi, A.A. and Wateba, M.I. (2019) Antiretroviral Therapeutic Profile in Patients Living with HIV with Chronic Kidney Disease. Advances in Infectious Diseases, 9, 252-262. https://doi.org/10.4236/aid.2019.93019

Received: July 25, 2019

Accepted: September 9, 2019

Published: September 12, 2019

Copyright ( 2019 by author(s) and Scientific Research Publishing Inc. This work is licensed under the Creative Commons Attribution International License (CC BY 4.0).

http://creativecommons.org/licenses/by/4.0/

\section{c) (†) Open Access}

\begin{abstract}
Chronic Kidney disease (CKD) is one of the important complications during HIV infection. The advent of Highly Active Antiretroviral Therapy (HAART) has significantly improved the prognosis of these patients. This was a descriptive and analytical cross-sectional study of people living with HIV received at the Ambulatory Treatment Center (ATC) of the Department of Infectious Diseases of Sylvanus Olympio University Hospital (CHU-SO). The study period was 6 months from January 1, 2018 to June 30, 2018. A total of 234 patients were enrolled during the study period. The mean age of patients at initiation of treatment was $42.07 \pm 9.49$ years with an average duration of follow-up under antiretroviral treatment of $5.61 \pm 3.22$ years. The female sex was predominant $(70.09 \%)$ and a sex ratio $(\mathrm{M} / \mathrm{F})$ of 0.43 . Most people living with HIV were mostly classified at clinical stage 2 (30.77) and $3(31.62 \%)$ of WHO at initiation of HAART. The mean CD4 rate was $223.30 \pm 143.764$ at initiation of HAART and $462.58 \pm 202.723$ at the time of study. The frequency of CKD was $11.11 \%$. The majority of patients were placed in a fixed combination of Tenofovir/Lamivudine/Efavirenz in a proportion of $81.20 \%$ of cases. In univariate analysis shows that age greater than 45 years $(p=0.017)$. Pathological proteinuria $(\mathrm{p}=0.021)$ were associated with CKD. In multivariate analysis, only age $(\mathrm{p}=0.045)$ and pathological proteinuria $(\mathrm{p}=0.035)$ were significantly associated with CKD.
\end{abstract}

\section{Keywords}

Therapeutic Profile, CKD, HIV, HAART, Togo 


\section{Introduction}

The prevalence of Human Immunodeficiency Virus (HIV) infection is high in the African region, with more than 25.7 million people living with HIV [1]. In 2017, Africa alone accounted for 25.7 million people living with HIV (PLHIV) [1]. In 2017, in Togo, the average prevalence in the general population aged 15 to 45 increased from $2.5 \%$ to $2.1 \%$ [2]. The survival of people living with HIV depends on several factors: early diagnosis of HIV infection, early antiretroviral therapy and especially adherence to treatment [3] [4] [5]. In 2019, in Togo, the incidence of kidney disease is high (41.8\%) in HIV-infected ART naive patients [6].

Since the advent of Highly Active Antiretroviral Therapy (HAART), the prognosis of patients has been greatly improved. There has been a decrease in the frequency of opportunistic infections and mortality [7]. Opportunistic infections accounted for more than $40 \%$ in the early 2000 s, and only $15 \%-20 \%$ in the most recent series [8] [9].

The increase in the life expectancy of patients treated with HAART is accompanied by an increase in the incidence of age-related diseases (diabetes and high blood pressure in particular), possible co-infections with hepatitis B and C viruses and late complications of HIV infection, including arteriosclerosis and cancers other than those defining AIDS [10] [11] [12]. These different factors contribute to the increase in the prevalence of chronic kidney disease in HIV-infected patients [13]. In Togo, this is the first ever study conducted to determine the therapeutic profile of HIV-infected patients with Chronic Kidney disease $(\mathrm{CKD})$.

\section{Patients and Methods}

This was a descriptive and analytical cross-sectional study of people living with HIV received at the Ambulatory Treatment Center (ATC) of the Infectious Diseases Department of the Sylvanus Olympio University Hospital (CHU-SO) for their follow-up consultation. The study period was 6 months from January 2018 to June 30, 2018. The infectious and tropical diseases department of the CHU-SO is the reference service for the care of patients infected with HIV. The patients included in this study were known PLHIV over 15 years of age, who have been regularly monitored at ATC for at least 3 months on ART (Antiretroviral treatment). Each patient had two creatinines (at initiation of treatment and at 3 months) and a urine test for proteinuria. It is in this population of patients included that we have identified those with chronic kidney disease.

Proteinuria was said to be pathological with a urinary strip if it was positive at one or more crosses. Treatment initiation information such as WHO (World Health Organization) clinical course, CD4 count, serum creatinine and antiretroviral therapy molecules were collected in the medical management record. Not included were children, pregnant women or naive patients with HAART during the study period and those without a minimum baseline nephrological checkup (at least one three-month-old serum creatinine, urinary tape proteinuria). 
The variables studied were sociodemographic parameters (age, sex and level of education); anthropometric parameters (weight, height and Body Mass Index (BMI)); clinical and biological parameters (WHO clinical stage of HIV (Table 3) at initiation of HAART, CD4 count) and antiretroviral therapy lines. Patients' creatinine clearance was estimated by the simplified MDRD formula [14]. CKD was defined as a clearance less than $60 \mathrm{ml} / \mathrm{min} / 1.73 \mathrm{~m}^{2}$ for at least 3 months. CKD was classified into 5 stages according to K-DIGO [15]. Age was divided into two categories: higher or lower than 45 years old. This age was randomly selected.

Definition of operational terms:

- High Blood Pressure (HBP) was defined as a systolic blood pressure above $140 \mathrm{mmHg}$ and a diastolic blood pressure as above $90 \mathrm{mmHg}$.

- Diabetes is defined as fasting blood sugar levels above $1.21 \mathrm{~g} / \mathrm{l}$.

- $\mathrm{BMI}$ is classified according to WHO in 4 stages [16].

- The CD4 count is divided into two categories: low if less than 200 cells/microliter and not low if greater than 200 cells/microliter.

Data collection was performed using Epidata 3.1 software; analysis was performed using SPSS software version 13.0 and R software. A univariate and multivariate comparative analysis with a logistic regression of socio-demographic, clinical and therapeutic data of CKD versus non-CKD patients was performed with statistical tests (Pearson's Chi-square test and Fisher's test). One variable was considered significantly associated with CKD if $\mathrm{p}<0.05$.

\section{Results}

\subsection{Descriptive Aspect}

A total of 1300 patients were followed at the CTA during the study period, but only 234 patients met the inclusion criteria. Of the 234 patients, 26 had CKD. The prevalence of CKD was $11.11 \%$. The average age of patients at initiation of treatment was $42.07 \pm 9.49$ and at the time of the study was $47.68 \pm 9.88$ with an average follow-up time on HAART of $5.61 \pm 3.22$ years. The female sex was predominant $(70.09 \%)$ and a sex ratio $(\mathrm{M} / \mathrm{F})$ of 0.43 . Of these PLHIV on HAART, $87.6 \%$ did not have a first cycle patent (Table 1). High blood pressure was found in $13.68 \%$ of enrolled patients and diabetes in $1.71 \%$ of cases. The average body mass index (BMI) was $23.80 \mathrm{~kg} / \mathrm{m}^{2}$. Overweight and obesity were

Table 1. Level of education of HIV-infected patients with CKD.

\begin{tabular}{ccc}
\hline Level of education & Effective (n) & Percentage (\%) \\
\hline None & 65 & 27.8 \\
Primary & 65 & 27.8 \\
Middle School & 75 & 32 \\
Secondary school & 19 & 8.1 \\
High & 10 & 4.3 \\
Total & 234 & 100.00 \\
\hline
\end{tabular}


found in $26.50 \%$ and $8.54 \%$ of cases respectively (Table 2). Pathological proteinuria was present in $25.64 \%$ of patients. The average creatinine clearance was $58.25 \pm 10.48 \mathrm{ml} / \mathrm{min} / 1.73 \mathrm{~m}^{2}$.

The majority of PLHIV were classified as WHO clinical stage $2(30.77 \%)$ and $3(31.62 \%)$ when initiating HAART (Table 3$)$. The average CD4 count was $223.30 \pm 143.764$ at initiation of HAART and $462.58 \pm 202.723$ at the time of study. At the therapeutic level, the majority of patients were placed on a fixed combination of Tenofovir/Lamivudine/Efavirenz in $81.20 \%$ of cases. The remaining data on HAART are summarized in Tables 4-6.

\subsection{Comparative Analysis}

Univariate analysis shows that age greater than 45 years is associated $(\mathrm{RR}=4.71$,

Table 2. Patient distribution according to weight class.

\begin{tabular}{cccc}
\hline Interpretation of BMI & Frequency & Percentage & Cumulative Percentage \\
\hline Underweight & 28 & 11.97 & 11.97 \\
Normal BMI & 124 & 52.99 & 64.96 \\
Overweight & 62 & 26.50 & 91.45 \\
Moderate obesity & 14 & 5.98 & 97.44 \\
Morbid obesity & 6 & 2.56 & 100.00 \\
Total & 234 & 100.00 & \\
\hline
\end{tabular}

BMI: Body Mass Index.

Table 3. Distribution of HIV-infected patients according to WHO clinical stage.

\begin{tabular}{ccc}
\hline Initiation stages & Effective (n) & Percentage (\%) \\
\hline Stage 1 & 48 & 20.51 \\
Stage 2 & 72 & 30.77 \\
Stage 3 & 74 & 31.62 \\
Stage 4 & 40 & 17.1 \\
Total & 234 & 100.00
\end{tabular}

Table 4. Distribution of antiretrovirals used in patients.

\begin{tabular}{cccc}
\hline Prescribed molecules & Yes & No & Total \\
\hline Tenofovir (TDF) & $222(94.87)$ & $12(5.13)$ & $234(100)$ \\
Efavirenz (EFV) & $196(83.76)$ & $38(16.24)$ & $234(100)$ \\
Atazanavir (ATV) & $30(12.82)$ & $204(87.18)$ & $234(100)$ \\
Zidovudine (AZT) & $6(2.56)$ & $228(97.44)$ & $234(100)$ \\
Abacavir (ABC) & $6(2.56)$ & $228(97.44)$ & $234(100)$ \\
Lopinavir (LOP) & $6(2.56)$ & $228(97.44)$ & $234(100)$ \\
Nevirapine (NEV) & $2(0.85)$ & $232(99.15)$ & $234(100)$ \\
\hline
\end{tabular}


Table 5. Distribution according to HAART therapeutic diagrams.

\begin{tabular}{ccc}
\hline Type of triple therapy & Effective $(\mathbf{n})$ & Percentage $(\mathbf{n})$ \\
\hline TDF/3TC/EFV & 190 & 81.20 \\
TDF/3TC/ATV & 26 & 11.11 \\
TDF/3TC/LOP & 6 & 2.56 \\
ABC/3TC/EFV & 6 & 2.56 \\
AZT/3TC/ATV & 4 & 1.71 \\
AZT/3TC/NEV & 2 & 0.85 \\
Total & 234 & 100.00 \\
\hline
\end{tabular}

HAART: Highly Active Antireviral Therapy.

Table 6. Distribution of patients according to different treatment lines.

\begin{tabular}{ccc}
\hline Current treatment line & Effective (n) & Percentage (\%) \\
\hline Line 1 & 198 & 84.62 \\
Line 2 & 36 & 15.38 \\
Total & 234 & 100.00 \\
\hline
\end{tabular}

Line 1: TDF/3TC/EFV; ABC/3TC/EFV; AZT/3TC/NEV. Line 2: TDF/3TC/ATV; TDF/3TC/LOP; AZT/3TC/AT.

95\% IC $=[1.09,20.34])$ with CKD $\mathrm{p}=0.017($ Table 7$)$. Sex $(\mathrm{p}=0.339)$, body mass index (BMI) RR $=0.82 ; 95 \% \mathrm{IC}=[0.27 ; 2.51]$, clinical stage of HIV, history of hypertension $(\mathrm{HBP}) \mathrm{RR}=2.81 ; 95 \% \mathrm{IC}=[0.98 ; 8.04]$ or diabetes $\mathrm{RR}=4.79$; $95 \%$ IC $=[1.08 ; 21.17]$ were not associated with CKD. The existence of pathological proteinuria was associated with $\mathrm{CKD}(\mathrm{RR}=3.38$; 95\% IC $=[1.23 ; 9.27](\mathrm{p}$ $=0.0021)$ ). With respect to anti-retroviral drugs administered to patients, none was associated with the occurrence of CKD (Table 8).

In multivariate analysis, only age and pathological proteinuria were significantly associated with CKD (OR of $5.50(\mathrm{p}=0.045))$ and (OR $4.11(\mathrm{p}=0.045))$, respectively (Table 9).

\section{Discussion}

To our knowledge, this is the very first study conducted in our country to determine the antiretroviral therapeutic profile of PLHIV with CKD. The limitations of our study lie in the small size of the sample because the infectious diseases department of our center is not the only care center; however, the results found make it possible to document the African literature in the sense that it is the reference center for HIV care in Togo. Attolou et al. reported in their series a population of 92 patients with similar results [17]. The prevalence of CKD in our sample was $11.11 \%$. This prevalence varies according to the studies and depends on the population studied and the method used to estimate the eGFR [18]. Zannou et al. found $18.7 \%$ in a Beninese population of $480 \mathrm{HIV}$-infected people using the Cockcroft and Gault formula; the median age was $41.4 \pm 9.16$ years old [19]. The elevation of creatinine levels $(\geq 15 \mathrm{mg} / \mathrm{l})$ was used in another study; it 
Table 7. Univariate analysis of sociodemographic and clinical data.

\begin{tabular}{|c|c|c|c|c|c|c|}
\hline \multirow{2}{*}{ Characteristics } & \multicolumn{2}{|c|}{$\mathrm{CKD}+(\mathrm{N}=26)$} & \multicolumn{2}{|c|}{ CKD- $(\mathrm{N}=208)$} & \multirow{2}{*}{ OR IC 95\% } & \multirow{2}{*}{$\mathrm{P}$} \\
\hline & $\mathrm{N}$ & (\%) & $\mathrm{N}$ & (\%) & & \\
\hline Sexe & & & & & $1.21[0.90 ; 3.60]$ & 0.339 \\
\hline Male & 4 & 15.38 & 66 & 31.73 & & \\
\hline Female & 22 & 84.62 & 142 & 68.27 & & \\
\hline Age (years) & & & & & $4.17[1.09 ; 20.34]$ & 0.017 \\
\hline$\leq 45$ & 43 & 15.38 & 104 & 50.00 & & \\
\hline$>45$ & 22 & 84.62 & 104 & 50.00 & & \\
\hline HBP & & & & & $2.81[0.98 ; 8.04]$ & 0.078 \\
\hline Yes & 8 & 30.77 & 24 & 11.54 & & \\
\hline No & 18 & 69.23 & 184 & 88.46 & & \\
\hline Diabetes & & & & & $4.79[1.08 ; 21.17]$ & 0.21 \\
\hline Yes & 2 & 7.69 & 2 & 0.96 & & \\
\hline No & 24 & 92.31 & 206 & 99.04 & & \\
\hline BMI $\left(\mathrm{kg} / \mathrm{m}^{2}\right)$ & & & & & $0.82[0.27 ; 2.51]$ & 0.49 \\
\hline$<25$ & 8 & 30.77 & 74 & 35.58 & & \\
\hline$\geq 25$ & 18 & 69.23 & 134 & 64.42 & & \\
\hline WHO Clinical Stage & & & & & - & 0.857 \\
\hline Stage 1 & 6 & 23.08 & 42 & 20.20 & & \\
\hline Stage 2 & 10 & 38.46 & 62 & 29.82 & & \\
\hline Stage 3 & 8 & 30.77 & 68 & 32.69 & & \\
\hline Stage 4 & 2 & 7.69 & 36 & 17.29 & & \\
\hline Pathological proteinuria & & & & & $3.38[1.23 ; 9.27]$ & 0.021 \\
\hline Yes & 14 & 53.85 & 46 & 22.12 & & \\
\hline No & 12 & 46.15 & 162 & 77.88 & & \\
\hline CD4 rate & & & & & $8.58[0.31 ; 4.51]$ & 0.51 \\
\hline$<200$ & 14 & 53.85 & 104 & 50 & & \\
\hline$\geq 200$ & 12 & 46.15 & 104 & 50 & & \\
\hline
\end{tabular}

BMI: Body Mass Index; HBP: High Blood Pressure; WHO: World Health Oragnization.

Table 8. Univariate analysis of antiretroviral related characteristics.

\begin{tabular}{ccccccc}
\hline \multirow{2}{*}{ Characteristics } & \multicolumn{2}{c}{$\mathrm{CKD}+(\mathrm{N}=26)$} & \multicolumn{2}{c}{$\mathrm{CKD}-(\mathrm{N}=208)$} & OR IC 95 \% & P \\
\cline { 2 - 4 } & $\mathbf{N}$ & $(\%)$ & $\mathbf{N}$ & $(\%)$ & & \\
\hline TDF & & & & & $0.65[0.1 ; 4.2]$ & 0.515 \\
Yes & 24 & 92.31 & 198 & 95.19 & & \\
No & 2 & 7.69 & 10 & 4.81 & & 0.22 \\
EFV & & & & & $0.44[0.15 ; 1.27]$ & 0.22 \\
Yes & 18 & 69.23 & 178 & 85.58 & & \\
\hline
\end{tabular}




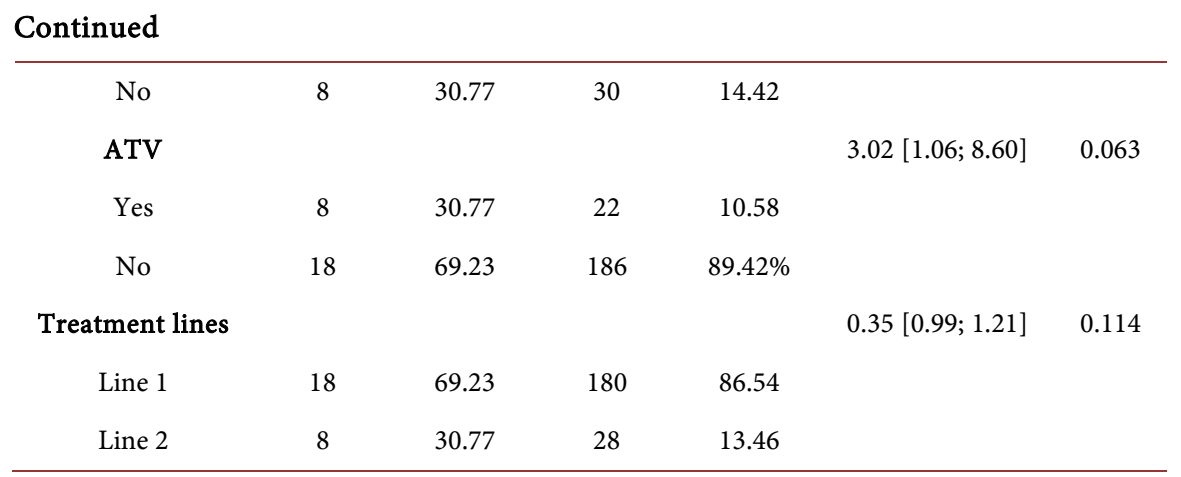

Table 9. Multivariate analysis of characteristics associated with CKD.

\begin{tabular}{cccc}
\hline Characteristics & Adjusted OR & IC95\% adjusted & P \\
\hline Age & 5.50 & {$[1.16 ; 26.03]$} & 0.045 \\
HBP & 2.36 & {$[0.51 ; 10.82]$} & 0.266 \\
Diabetes & 3.87 & {$[0.20 ; 73.76]$} & 0.368 \\
Proteinuria & 4.11 & {$[1.26 ; 13.43]$} & 0.035 \\
HAART & - & - & 0.999 \\
HAART Line & - & - & 0.999 \\
\hline
\end{tabular}

HBP: High Blood Pressure; HAART: Highly Active Antireviral Therapy.

gave a prevalence of $31.1 \%$ with a mean age of $34.6 \pm 9.4$ years [20]. In contrast, Umeizudike et al. [21] found $23.5 \%$ with an average age of $35 \pm 8.3$ years. It was generally accepted in Sub-Saharan Africa that CKD prevalence ranged from 6 to 48.5\% in HIV-infected patients [22]. Contrary to this observation, studies conducted in Europe in caucasian subjects showed a prevalence around $4 \%$; in France for example, it was only $4.7 \%$ in a population of 7378 patients using the MDRD formula [23]. The analysis of Hsieh M.-H. et al. [24] in Taiwan after finding a prevalence of $7.9 \%$ in its population unlike other Asian studies (15.4\% in Japan and $16.8 \%$ in Hong Kong), showed that age had an impact on CKD prevalence in the HIV-infected population. It should be noted that the prevalence of CKD increased after the age of 40 [22]. Consistent with this observation, the average age of $42.07 \pm 9.49$ years in our study, would partly explain the superiority of our prevalence to other studies such as Umeizudike et al. [21]. In addition, the genetic susceptibility of the black subject to develop CKD must be added [25]. Nevertheless, our prevalence may be considered underestimated because of the small size of our sample.

In our study, we reported that age greater than 45 years with an OR of 5.5 ( $\mathrm{p}=$ 0.045) was associated with the occurrence of CKD. Zannou et al. [19] in Cotonou found that age $\geq 47$ years with an $\mathrm{OR}=3.79$ and IC $=[1.92-7.50](\mathrm{p}<$ 0.001) was associated with CKD; in New York Wyatt et al. [26] had found an age slightly older than $50(p<0.0001)$. The age of occurrence of CKD in HIV-infected patients is early in the majority of studies involving black subjects [20] [25] [27]. This precocity could be explained on one hand by the genetic predisposition of 
black subjects to develop CKD characterized histologically by HIVAN (HIV Associated Nephropathy). On the other hand, the late diagnosis of the disease in our environments, most often at the complication stage, could be an element in favor. In addition, low CD4 levels are a risk factor for CKD in patients infected in some studies [20] [23]. Flandre et al. [23] found that having a TCD4 $\geq 200$ cells/microliter with a RR of 0.63 ( 0.48 to 0.81$)$ and $\mathrm{p}=0.03$ was associated with the occurrence of CKD. This correlation was not found in our study and also in others [19] [28]. HBP, diabetes and dyslipidemia are traditional risk factors for CKD in the general population and in HIV-infected patients. In our study $13.36 \%$ of patients were hypertensive. There was no correlation found between hypertension and CKD in our study. In Cotonou, Zannou et al. [19] found $12.3 \%$ of cases of hypertension and $3.1 \%$ of diabetes with ORs of 1.57 [0.83 $2.97](\mathrm{p}=0.17)$ and $0.30 \mathrm{IC}=[0.03-2.32](\mathrm{p}=0.17)$ respectively. In contrast, in France, Flandre et al. [23] found that $48 \%$ of patients with HIV were hypertensive and $9.8 \%$ were diabetic. They also observed that HBP was statically related to the occurrence of CKD with OR $=2.39$ and $\mathrm{p}<0.0001$. Min-Han Hsieh et al. [24] found a risk of developing CKD in HIV-infected patients with hypertension $(\mathrm{OR}=23.06, \mathrm{IC}=4.67-113.87$ and $\mathrm{p}<0.001)$ and diabetes $(\mathrm{OR}=9.822, \mathrm{IC}=$ $1.862-51.08, \mathrm{p}=0.007)$ and high cholesterol levels $(\mathrm{OR}=5.52$ and $\mathrm{IC}=1.23$ $4.68, \mathrm{p}=0.025)$. In the USA, Schwartz al [20] had shown that the presence of hypertension is a marker of high-risk of developing CKD. This observed difference can be explained by the sample sizes of the different studies. Indeed, studies that found hypertension and diabetes as a risk factor had a relatively large sample size. Moreover, the fact that the presence of hypertension and diabetes in HIV patients under treatment is not statically related to the occurrence of CKD in our study may be explained by the fact that hypertension and diabetes although traditional risk factors for $\mathrm{CKD}$, were probably not the main causes of kidney disease in Black HIV-infected patients.

In our study, pathological proteinuria was a risk factor for CKD. Zannou et al. [19] did not reach the same conclusion in their study in Benin. Nevertheless, the association of proteinuria with CKD in HIV-infected patients is an indicator of the importance of managing these patients. Because in the absence of treatment, it progresses on average in two years in CKD and it is responsible for $50 \%$ of cases of ESRD (End-Stage Renal Disease) [29]. The fixed-combination therapy based on Tenofovir/Lamivudine/Efavirenz was the most commonly found in our series; and no antiretroviral therapy line was associated with the occurrence of CKD. CKD involves pathophysiological changes that will influence not only the renal excretion of endogenous substances, but also the excretion of drugs and in particular HAART. The management of HAART in a patient with renal failure requires close collaboration between nephrologists and infectiologists because of the diversity of situations encountered, the multiple potential drug interactions, the variability of absorption after enteral administration and the frequency of associated acute or CKD [30]. The problem often encountered in our developing 
countries is the administration of doses that are sometimes not commercially available on the market. The majority of our patients were on Tenofovir. Tenofovir, a nucleotide inhibitor of HIV reverse transcriptase, is the main HAART involved and causes up to $70 \%$ of the drug tubulopathies observed in these patients [31]. This molecule may be responsible for proximal tubular lesions. Tenofovir treatment should be permanently interrupted in the event of Fanconi syndrome or acute renal failure due to this drug [32].

\section{Conclusion}

CKD is common in HIV-infected patients. The frequency of chronic kidney disease remains high with an increase related to age, comorbidities and chronic toxicity some HAART molecules. The dramatic improvement in the long-term survival of patients treated with HAART encourages better collaboration between nephrologists and infectiologists.

\section{Conflicts of Interest}

The authors declare no conflicts of interest regarding the publication of this paper.

\section{References}

[1] World Health Organization (2019) Global Health Sector Strategy on HIV, 2016-2021: Key Facts on HIV/AIDS. https://www.who.int/fr/news-room/fact-sheets/detail/hiv-aids

[2] Programme National de Lutte Contre le Sida et les IST (2017) RAPPORT ANNUEL PNLS. http://www.pnls.tg/rapports/RAPPORT\%20ANNUEL\%20PNLS\%202017.pdf

[3] Brinkhof, M., Boulle, A., Weigel, R., Messou, E., Mathers, C., Orrell, C., et al. (2009) Mortality of HIV-Infected Patients Starting Antiretroviral Therapy in Sub-Saharan Africa: Comparison with HIV-Unrelated Mortality. PLoS Medicine, 6, e1000066. https://doi.org/10.1371/journal.pmed.1000066

[4] Mayben, J.K., Kramer, J.R., Kallen, M.A., Franzini, L., Lairson, D.R. and Giordano, T.P. (2007) Predictors of Delayed HIV Diagnosis in a Recently Diagnosed Cohort. AIDS Patient Care and STDs, 21, 195-204. https://doi.org/10.1089/apc.2006.0097

[5] Shah, S.S., Crane, M., Monaghan, K. and McGowan, J.P. (2004) Genotypic Resistance Testing in HIV-Infected Pregnant Women in an Urban Setting. International Journal of STD \& AIDS, 15, 384-387. https://doi.org/10.1258/095646204774195236

[6] Sabi, K.A., Dolaama, B., Amekoudi, E.Y.M., Kotosso, A., Noto-Kadou-Kaza, B., Tsevi, C.M., Tona, K.G., Attisso, E.A., Bonou-Selegbe, S., Ibrahim, H., Mahamat, G.A., Vigan, J. and Wateba, M.I. (2019) Epidemiological, Clinical and Biological Aspects of Kidney Disease in People Living with HIV Naive Antiretroviral Therapy at CHU Sylvanus Olympio of Lome (TOGO). Open Journal of Nephrology, 9, 26-34. https://doi.org/10.4236/ojneph.2019.91003

[7] Laparra, N., Martínez, F., Giner, V., Monteagudo, C., Galindo, M.J., Alcácer, F., Redón, J., et al. (2010) Evolución temporal de la afectación renal en una serie necrópsica de pacientes VIH de las eras pre y TARGA. Nefrología, 30, 420-426.

[8] Barbier, F., Roux, A., Canet, E., et al. (2014) Temporal Trends in Critical Events Complicating HIV Infection: 1999-2010 Multicentres Cohort Study in France. In- 
tensive Care Medicine, 40, 1906-1915. https://doi.org/10.1007/s00134-014-3481-7

[9] Akgun, K.M., Tate, J.P., Pisani, M., et al. (2013) Medical ICU Admission Diagnoses and Outcomes in Human Immunodeficiency Virus-Infected and Virus-Uninfected Veterans in the Combination Antiretroviral Era. Critical Care Medicine, 41, 1458-1467. https://doi.org/10.1097/CCM.0b013e31827caa46

[10] Smith, C.J., Ryom, L., Weber, R., et al. (2014) Trends in Underlying Causes of Death in People with HIV from 1999 to 2011 (D:A:D): A Multicohort Collaboration. The Lancet, 384, 241-248. https://doi.org/10.1016/S0140-6736(14)60604-8

[11] Deeks, S.G., Lewin, S.R. and Havlir, D.V. (2013) The End of AIDS: HIV Infection as a Chronic Disease. The Lancet, 382, 1525-1533. https://doi.org/10.1016/S0140-6736(13)61809-7

[12] Akgun, K.M., Huang, L., Morris, A., et al. (2011) Critical Illness in HIV-Infected Patients in the Era of Combination Antiretroviral Therapy. Proceedings of the American Thoracic Society, 8, 301-307. https://doi.org/10.1513/pats.201009-060WR

[13] Mallipattu, S.K., Salem, F. and Wyatt, C.M. (2014) The Changing Epidemiology of HIV-Related Chronic Kidney Disease in the Era of Antiretroviral Therapy. Kidney International, 86, 259-265. https://doi.org/10.1038/ki.2014.44

[14] Levey, A.S., Coresh, J., Bolton, K., Culleton, B., Harvey, K.S., Ikizler, T.A., Levin, A., et al. (2002) K/DOQI Clinical Practice Guidelines for Chronic Kidney Disease: Evaluation, Classification, and Stratification. American Journal of Kidney Diseases, 39, Suppl. 1.

[15] Levey, A.S., Eckardt, K.U., Tsukamoto, Y., et al. (2005) Definition and Classification of Chronic Kidney Disease: A Position Statement from Kidney Disease: Improving Global Outcomes (KDIGO). Kidney International, 67, 2089-2100. https://doi.org/10.1111/j.1523-1755.2005.00365.x

[16] Organisation Mondiale de la Santé (2014) Classification de l'obésité et du surpoids. https://www.calculersonimc.fr/classifications-tranches-imc.html

[17] Attolou, V., Bigot, A., Ayivi, B., et al. (1998) Complications rénales associées à l'infection par le virus de l'immunudéficience humaine dans une population hospitalisée au CNHU de Cotonou. Cahier d'Etudes et de recherches francophonel santé, 8, 283-290.

[18] Mohanram, A., Zhang, Z., Shahinfar, S., Keane, W.F., Brenner, B.M. and Toto, R.D. (2004) Anemia and End-Stage Renal Disease in Patients with Type 2 Diabetes and Nephropathy. Kidney International, 66, 1131-1138. https://doi.org/10.1111/j.1523-1755.2004.00863.x

[19] Zannou, D.M., Vigan, J., Azon-Kouanou. A., Agboton, B.L. and Houngbe, C.M.B. (2015) Prevalence of Chronic Kidney Failure and Associated Factors in Patients Treated by Antiretroviral in the National Teaching Hospital of Cotonou. Journal of Nephrology \& Therapeutics, 5, 214. https://doi.org/10.4172/2161-0959.1000214

[20] Schwartz, E.J, Szczech, L.A., Ross, M.J., Klotman, M.E., Winston, J.A. and Klotman, P.E. (2005) Highly Active Antiretroviral Therapy and the Epidemic of HIV+ End-Stage Renal Disease. Journal of the American Society of Nephrology, 16, 2412-2420.

[21] Umeizudike, T., Mabayoje, M., Okany, C., Abdulkareem, F., Adeyomoye, A., Okubadejo, N., et al. (2012) Prevalence of Chronic Kidney Disease in HIV Positive Patients in Lagos, South-West Nigeria. Nephrology Research \& Reviews, 4, 22-26. https://doi.org/10.4081/nr.2012.e5

[22] Bashi, J., Balestre, E., Messou, E., Maiga, M., Coffie, P.A., Zannou, D.M., et al. (2010) Évolution des conditions d'initiation du traitement antirétroviral des pa- 
tients infectés par le VIH en Afrique de l'Ouest. Médecine et Maladies Infectieuses, 40, 449-455.

[23] Flandre, P., Pugliese, P., Cuzin, L., Bagnis, C.I., Tack, I., Cabié, A., et al. (2011) Risk Factors of Chronic Kidney Disease in HIV-Infected Patients. Clinical Journal of the American Society of Nephrology, 6, 1700-1707. https://doi.org/10.2215/CJN.09191010

[24] Hsieh, M.H., et al. (2015) Prevalence of and Associated Factors with Chronic Kidney Disease in Human Immunodeficiency Virus-Infected Patients in Taiwan. Journal of Microbiology, Immunology and Infection, 8, 256-262.

[25] Vrouenraets, S.M., Fux, C.A., Wit, F.W., Garcia, E.F., Brinkman, K., Hoek, F.J., et al. (2012) A Comparison of Measured and Estimated Glomerular Filtration Rate in Successfully Treated HIV-Patients with Preserved Renal Function. Clinical Nephrology, 77, 311-320. https://doi.org/10.5414/CN107214

[26] Wyatt, C.M., Winston, J.A., Malvestutto, C.D., Fishbein, D.A., Barash, I., Cohen, A.J., et al. (2007) Chronic Kidney Disease in HIV Infection: An Urban Epidemic. AIDS, 21, 2101-2103. https://doi.org/10.1097/QAD.0b013e3282ef1bb4

[27] Kitiyakara, C., Kopp, J.B. and Eggers, P. (2003) Trends in the Epidemiology of Focal Segmental Glomerulosclersis. Seminars in Nephrology, 23, 172-182. https://doi.org/10.1053/snep.2003.50025

[28] Amat-Roze, J.M. (1989) L'infection à V.I.H. et le SIDA en Afrique noire: Facteurs d'épidémisation et de régionalisation. Les Cahiers d Outre-Mer, 42, 333-355. https://doi.org/10.3406/caoum.1989.3318

[29] Winston, J., Deray, G., Hawkins, T., Szczech, L., Wyatt, C., et al. (2008) Kidney Disease in Patients with HIV Infection and AIDS. Clinical Infectious Diseases, 47, 1449-1457. https://doi.org/10.1086/593099

[30] Gallien, S. and Molina, J.M. (2011) Ce que le réanimateur doit connaître des antirétroviraux. Réanimation, 20, 234-241. https://doi.org/10.1007/s13546-011-0254-y

[31] Zaidan, M., Lescure, F.X., Brocheriou, I., et al. (2013) Tubulointerstitial Nephropathies in HIV-Infected Patients over the Past 15 Years: A Clinico-Pathological Study. Clinical Journal of the American Society of Nephrology, 8, 930-938. https://doi.org/10.2215/CJN.10051012

[32] Lucas, G.M., Ross, M.J., Stock, P.G., et al. (2014) Clinical Practice Guideline for the Management of Chronic Kidney Disease in Patients Infected with HIV: 2014 Update by the HIV Medicine Association of the Infectious Diseases Society of America. Clinical Infectious Diseases, 59, e96-e138. https://doi.org/10.1093/cid/ciu617 